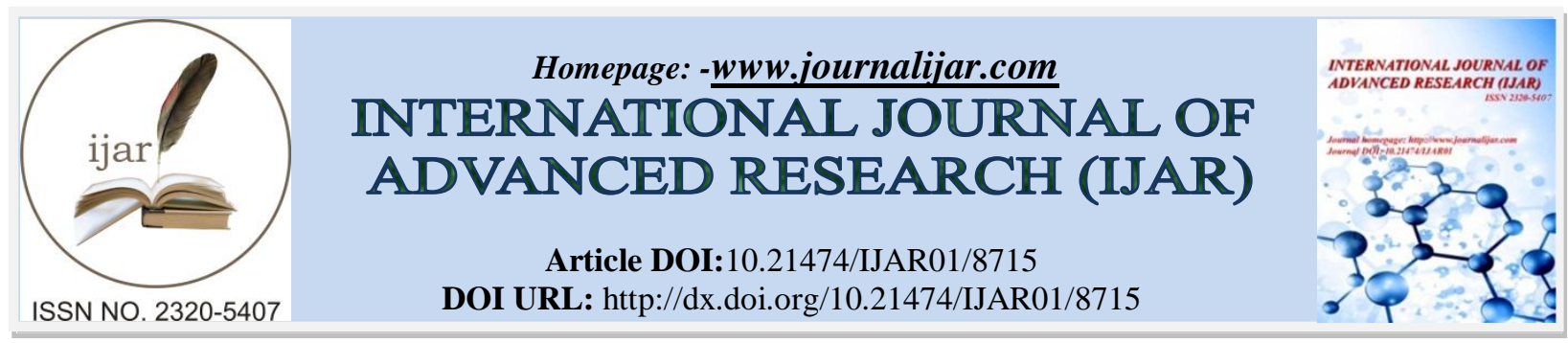

RESEARCH ARTICLE

\title{
A STUDY ON JOB SATISFACTION WITH REFERENCE TO TRANSPORT EMPLOYEES IN KUMBAKONAM REGION, TAMILNADU.
}

\author{
Nagendra $\mathrm{HM}^{1}$ and Dr. P. Asokan ${ }^{2}$. \\ 1. Research Scholar, Department of commerce, Bharathiar University, Coimbatore. \\ 2. Associate Professor, Department of Commerce, Thiru.Vi.Ka.Govt.Arts College, Tiruvarur.
}

\section{Manuscript Info}

Manuscript History

Received: 16 January 2019

Final Accepted: 18 February 2019

Published: March 2019

Key words:-

Road Transport, Job Satisfaction.

\begin{abstract}
Road transport plays an important role in the economy of the country and is particularly suitable for short and medium distances. It also offers a number of other advantages such as flexibility, reliability, speed and door to door service. No system can be said to have 100 per cent perfection in all respects. It is practically impossible to offer such a system or organization, and every system has got its own merits and demerits. If a system or organization is not properly managed, inefficiency creeps, which leads to heavy losses. The loss does not mean financial loss or personal loss of the individual, but in a larger sense a loss to the society.
\end{abstract}

Copy Right, IJAR, 2019,. All rights reserved.

\section{Introduction:-}

Road transport is the basic and fundamental necessity of mankind. It can function in an unexceptionally flexible and diversified manner in relation to other means of transport. It plays an important role in the passenger transportation of the country and is particularly suitable for all short and long distance travels". Road transport plays an important role in the economy of the country and is particularly suitable for short and medium distances. It also offers a number of other advantages such as flexibility, reliability, speed and door to door service. Road transport thus forms an indispensable element of the national transport system. The share of road transport in recent years to overall traffic has been continuously increasing. No system can be said to have 100 per cent perfection in all respects. It is practically impossible to offer such a system or organization, and every system has got its own merits and demerits. If a system or organization is not properly managed, inefficiency creeps, which leads to heavy losses. The loss does not mean financial loss or personal loss of the individual, but in a larger sense a loss to the society. ${ }^{1-3}$

\section{Importance Of The Study:-}

Normally job-satisfaction leads to higher performance or productivity. A well satisfied worker will take initiative in improving his performance. But researchers have proved that this assumption is not always correct. For example, a satisfied worker may be a high or low or average performer. Being influenced by several intervening variable such as reward, the relationship between satisfaction and performance becomes complex. According to Peter Lawler, productivity leads to better job satisfaction because performance attracts reward and reward result in job satisfaction. Job satisfaction survey reveals the feelings of the workers towards their jobs and work environment. It is a powerful diagnostic instrument for assessing the problems faced by the workers. ${ }^{4-5}$ 


\section{Objectives Of The Study:-}

The study "Job-Satisfaction among TNSTC workers in Tiruvarur" aims at the following objectives.

1. To examine the various theoretical concepts of job satisfaction

2. To know the opinion of transport workers regarding the monetary aspects of their work

3. To assess the satisfaction level of the transport workers regarding the work environment

4. To know the factors responsible for increasing or decreasing their job satisfaction.

5. To offer suitable suggestions for improving the satisfaction of the drivers and conductors over their jobs.

\section{Methodology:-}

The design of the study is descriptive in nature. The information required for the study was collected from both primary and secondary sources. Primary data were collected from the transport workers using an interview schedule specially prepared for that purpose. Secondary data were collected from various related books, magazines and from various websites of the Internet.

\section{Sampling:-}

There are several hundreds of transport workers in the Tiruvarur district. Since no other sampling technique can be effectively employed due to reasons beyond the control of the researcher, convenient sampling technique was administered in this study. Under convenience sampling method 150 transport workers, 75 each from drivers and conductors were selected. Great care was taken to include workers from different age groups, educational qualifications and experience in the occupation. For the purpose of the study, an Interview schedule was designed and administered on the respondents. Particulars were collected regarding the opinion and satisfaction levels of the present salary, promotional opportunities, job security, problems faced, in the occupation, factors that increase satisfaction levels and factors that decrease satisfaction levels.

\section{Limitations Of The Study:-}

1. The study is restricted to Tiruvarur district only.

2. The study is restricted to passenger transport bus drivers and conductors only.

3. The opinion of the workers alone is taken up for the study. Opinion of the officers are not considered.

4. The results of the study cannot be generalized to other areas due to changing environment of working conditions.

5. The study has not covered other details such as the attitude of the family members towards the work and standard of living of the workers, owing to time and money constraints.

Table 1:-Age Pattern

\begin{tabular}{|c|c|c|c|c|}
\hline \multirow[b]{2}{*}{ Age in Years } & \multicolumn{2}{|c|}{ 1) Drivers } & \multicolumn{2}{|c|}{ Conductors } \\
\hline & No. of Respondents & $\%$ & No. of Respondents & $\%$ \\
\hline Upto 30 & 10 & 13 & 11 & 15 \\
\hline $31-50$ & 38 & 51 & 36 & 48 \\
\hline $50 \&$ Above & 27 & 36 & 28 & 37 \\
\hline Total & 75 & 100 & 75 & 100 \\
\hline
\end{tabular}

Source:-Primary data

Table 1 shows the age wise classification of Transport workers selected for the study 87 percent of the bus drivers and 85 percent of the bus conductors are above 30 years of age.

Table 2:-Monthly Income

\begin{tabular}{|c|c|c|c|c|}
\hline \multirow[b]{2}{*}{ In Rs. (Per month) } & \multicolumn{2}{|c|}{ 2) Drivers } & \multicolumn{2}{|c|}{ Conductors } \\
\hline & No. of Respondents & $\%$ & No. of Respondents & $\%$ \\
\hline Below 5000 & 10 & 13 & 9 & 12 \\
\hline $5001-10000$ & 37 & 49 & 35 & 46 \\
\hline Above 10000 & 28 & 38 & 31 & 42 \\
\hline Total & 75 & 100 & 75 & 100 \\
\hline
\end{tabular}

Source: Primary data 
Table 2 shows the monthly income of the respondents selected for the study. 49 per cent of the drivers and 46 per cent of conductors have been receiving Rs.5001 to Rs. 10000 and 38 per cent of the drivers and 42 per cent of the conductors have been receiving more than Rs.10,000 as total monthly income from the transport corporation.

Table 3:-Opinion about Present Salary

\begin{tabular}{|l|c|c|c|c|}
\hline \multirow{2}{*}{ Opinion } & \multicolumn{2}{c|}{ Drivers } & \multicolumn{2}{c|}{ Conductors } \\
\cline { 2 - 5 } & No. of Respondents & \% & No. of Respondents & \% \\
\hline Strongly Dissatisfied & & 9 & & 11 \\
Dissatisfied & 7 & 43 & 35 & 46 \\
Somewhat satisfied & 32 & 48 & 32 & 43 \\
Strongly satisfied & -- & -- & -- & -- \\
No opinion & -- & -- & 100 \\
\hline \multicolumn{1}{|c|}{ Total } & 75 & 100 & 75 & \\
\hline
\end{tabular}

Source: Primary data

Salary is one of the factors, which motivates the workers in general. Table 3 shows that none of the transport employees are strongly satisfied with their present level of salary. Only 48 percent of the drivers and 43 percent of the conductors are somewhat satisfied with their present salary set up.

Table 4:-Opinion about Promotion Avenues

\begin{tabular}{|l|c|c|c|c|}
\hline \multirow{2}{*}{ Opinion } & \multicolumn{2}{|c|}{ 3) Drivers } & \multicolumn{2}{c|}{ Conductors } \\
\cline { 2 - 5 } & No. of Respondents & \% & No. of Respondents & \% \\
\hline \multirow{3}{*}{ Strongly Dissatisfied } & & & -- & -- \\
Dissatisfied & -- & -- & 33 & 44 \\
Somewhat satisfied & 70 & -- & 36 & 48 \\
Strongly satisfied & -- & -- & -- & 8 \\
No opinion & -- & 7 & 6 & 100 \\
\hline \multicolumn{1}{|c|}{ Total } & 5 & 100 & 75 & - \\
\hline
\end{tabular}

Source: Primary data

Promotion is the advancement of an employee to all better in terms of greater responsibilities, more prestige or status greater skill and specially increased rate of pay. The senior level conductors are finally promoted, as checkers whereas the drivers have little no chance of getting any promotion 93 percent of the bus drivers and 44 percent of the bus conductors are dissatisfied with the promotion awareness of the transport corporation.

Table 5:-Opinion about Yearly Increments

\begin{tabular}{|l|c|c|c|c|}
\hline \multicolumn{1}{|c|}{ Opinion } & \multicolumn{2}{c|}{ Drivers } & \multicolumn{2}{c|}{ Conductors } \\
\cline { 2 - 5 } & No. of Respondents & \% & No. of Respondents & \% \\
\hline & & & & \\
Strongly Dissatisfied & 4 & 53 & 3 & 4 \\
Dissatisfied & 40 & 42 & 33 & 44 \\
Somewhat satisfied & 31 & -- & -- & - \\
Strongly satisfied & -- & -- & -- & 100 \\
No opinion & -- & 100 & 75 & - \\
\hline \multicolumn{1}{|c|}{ Total } & 75 & & & \\
\hline
\end{tabular}

Source: Primary data

Annual increments to employees are given to motivate them for good performance and also to recognize their service. It is a monetary reward and considered as a positive incentive. Table 5 shows the satisfaction level of transport workers with regard to yearly increments. 53 per cent of the drivers and 52 per cent of the conductors are dissatisfied with the annual increments offered by the Corporation. The remaining 42 percent of Drivers and 44 percent of conductors are somewhat satisfied with the amount of increments. 
Table 6:-Opinion about Leave facilities

\begin{tabular}{|l|c|c|c|c|}
\hline \multirow{2}{*}{ Opinion } & \multicolumn{2}{|c|}{ Drivers } & \multicolumn{2}{c|}{ 4) Conductors } \\
\cline { 2 - 5 } & No. of Respondents & \% & No. of Respondents & \% \\
\hline & & & & \\
Strongly Dissatisfied & 3 & 4 & 4 & 46 \\
Dissatisfied & 33 & 52 & 35 & 48 \\
Somewhat satisfied & 39 & -- & 36 & -- \\
Strongly satisfied & -- & -- & -- & -- \\
No opinion & -- & 100 & 75 & 100 \\
\hline \multicolumn{1}{|c|}{ Total } & 75 & & 75 & \\
\hline
\end{tabular}

Source: Primary data

Generally there are three types of leaver provided to all employees. There are casual leave, sick leave and privilege leave. Almost all the drivers and conductors are satisfied with their leave facilities. Among them 52 percent of bus drivers and 48 percent of bus conductors of transport services are somewhat satisfied and the remaining are dissatisfied except a few who strongly dissatisfied with the leave facilities provided by the corporation.

Table 7:-Opinion about Job Security.

\begin{tabular}{|l|c|c|c|c|}
\hline \multirow{2}{*}{ Opinion } & \multicolumn{2}{|c|}{ Drivers } & \multicolumn{2}{c|}{ 5) Conductors } \\
\cline { 2 - 5 } & No. of Respondents & \% & No. of Respondents & \% \\
\hline \multirow{3}{*}{ Strongly Dissatisfied } & -- & -- & - & -- \\
Dissatisfied & -- & -- & -- & -- \\
Somewhat satisfied & 39 & 52 & 36 & 48 \\
Strongly satisfied & 33 & 44 & 35 & 6 \\
No opinion & 3 & 4 & 4 & 100 \\
\hline \multicolumn{1}{|c|}{ Total } & 75 & 100 & 75 & \\
\hline
\end{tabular}

Source: Primary data

Job security is one of the major factors, which affects an individuals physical and mental health. It generally improves job satisfaction favourably. The study reveals that 44 percent of the drivers and 46 percent of the conductors of the transport corporation are strongly satisfied with the job security. It is clear from the above table that none of the respondent is dissatisfied with the security position of their job.

Table 8:-Opinion about Grievance-RedressalProgrammes

\begin{tabular}{|l|c|c|c|c|}
\hline \multicolumn{1}{|c|}{ Opinion } & \multicolumn{2}{c|}{ Drivers } & \multicolumn{2}{c|}{ Conductors } \\
\cline { 2 - 5 } & No. of Respondents & \% & No. of Respondents & \% \\
\hline & & & & 3 \\
Strongly Dissatisfied & 3 & 4 & 2 & 49 \\
Dissatisfied & 35 & 49 & 37 & 48 \\
Somewhat satisfied & 37 & -- & -- & - \\
Strongly satisfied & -- & -- & -- & 100 \\
No opinion & -- & 100 & 75 & \\
\hline \multicolumn{1}{|c|}{ Total } & 75 & & & \\
\hline
\end{tabular}

Source: Primary data

Grievances exist in the minds of individuals are produced and dissipated by situations are fostered or healed by group pressures, are adjusted or mode worse by supervisors, and are nourished or dissolved by the climate in the organization which is affected by all the above factors and by the management". The study shows that 47 percent of the drivers are 49 study of the conductors are dissatisfied with the grievance redressalprogrammes of the transport corporation.

\section{Findings of the study:-}

1. The study reveals that as much as 87 percent of the bus drivers and 85 per cent of the bus conductors are above 30 years of age. 
2. 49 percent of the drivers and 46 percent of conductors have been receiving Rs. 5001 to Rs. 10000 and 38 percent of the drivers and 42 percent of the conductors have been receiving more than Rs.10,000 as total monthly income from the transport corporation.

3. None of the transport employees are strongly satisfied with their present level of salary. Only 48 percent of the drivers and 43 percent of the conductors are somewhat satisfied with their present salary set up.

4. None of the respondents are either strongly dissatisfied or strongly satisfied with the amount of fringe benefits available to them.

5. The senior level conductors are finally promoted as checkers whereas the drivers have little no chance of getting any promotion. 93 percent of the bus drivers and 44 percent of the bus conductors are dissatisfied with the promotion awareness of the transport corporation.

6. 53 per cent of the drivers and 52 per cent of the conductors are dissatisfied with the annual increments offered by the Corporation. The remaining 42 percent of Drivers and 44 percent of conductors are somewhat satisfied with the amount of increments.

7. The study reveals that 46 percent of both the drivers and conductors of the transport corporation are strongly satisfied with the job security.

8. The study shows that 47 percent of the drivers are 49 study of the conductors are dissatisfied with the grievance redressalprogrammes of the transport corporation.

9. 49 percent of the drivers and 46 percent of the conductors are somewhat satisfied with the training and medical programmes of the corporation. The remaining respondents are dissatisfied with the programmes.

\section{Suggestions:-}

1. Salary is the prime determinant of job satisfaction. Therefore the salary of the drivers and conductors need revision. The corporation has to take steps for revising the pay scales of the workers to improve their satisfaction level.

2. This high time for the management of the corporation to revise the promotion policy, which is the root cause for dissatisfaction among the workers especially drivers and conductors. If promotion to next cadre is not possible at least monetary benefits of the next cadre be provided to them .

3. Unless the drivers and conductors feel that their jobs are secured they can not work effectively. So the Corporation shall ensure job security of the drivers and conductors.

4. The present system grievance redressal is not satisfactory. So steps may be taken to modify them in order to satisfy the aggrieved parties effectively.

5. The corporation should take effective steps to improve the public relations. Drivers and conductors should be given due training in this regard.

\section{Conclusion:-}

The job satisfaction level among the drivers and conductors working in the State Road Transport Corporation is satisfactory and not detrimental. The drivers and Conductors expect something more from the corporation in term of salary, promotion, fringe benefits etc.,. The corporation shall come forward to provide more benefits and facilities to its workers so that their job satisfaction can be improved further.

\section{References:-}

1. Ahmed Nazimuddin and S.S. Jha :job stress: strain and social, Support, India Journal of Training and Development, May-June, 1989.

2. Ahmed Salma: Talent Retention: A Challenge, Personnel Today , vol.18 No.2,jukySeptember, 1997.

3. Alder A.: Understanding Human Nature, Greenberg, New York,1989.

4. Alder Ralph and Markus Millen: Communication skills and attitudes, Chartered Accountants Journal of New Zealand, December 1994.

5. Bhattacharya S.K.: Achieving managerial Excellence, Macmillan, New Delhi ,1989. 